\title{
INTERVIEW
}

\section{Teacher Cognition and Language Teacher Education: beliefs and practice. A conversation with Simon Borg}

\author{
Marilisa Birello \\ Universitat Autònoma de Barcelona, Barcelona, Spain
}

(Interview received 16 April 2012; final version received 26 April 2012)

Simon Borg is Professor of TESOL at the School of Education of the University of Leeds in the United Kingdom. He teaches MA TESOL modules on Teacher Education and Grammar Teaching. He is on the editorial boards of Language Teaching Research and The Asian EFL Journal. His main area of research in TESOL focuses on language teacher cognition - i.e., the study of what language teachers know, believe, think and do. He has published numerous articles in scholarly journals such as Language Teaching, System, Language Teaching Research, and ELT Journal, and the books Teacher Cognition and Language Education (2008) and Teacher research in language teaching: A critical analysis (forthcoming, 2013).

INTERVIEWER: What is the importance of the study of beliefs in language teacher training? And why is this study important?

SIMON BORG: If we go back about 40 years in the field of teacher education, the focus was mostly on behaviors, so what researches were trying to do was discover behaviors that led to effective learning. The idea was once we know what they are, we can program teachers to behave in those ways and the results would be effective learning for everyone. That was quite a simplistic notion of teaching and learning. What started to become evident was that no matter how much you try to program teachers to behave in certain ways they won't; they always have their own individual ideas, their individual ways of doing things, their preferences, and so it started to become clear that teaching is much more than behavior. Beneath the behavior there are beliefs and knowledge and related constructs which influence what teachers do, and it started to become very clear that if we want to fully understand what teachers do, we can't just focus on behavior, we need to understand what they believe, what they know, their attitudes, their feelings. This became particularly true when we looked at large scale educational reforms which never seemed to have the desired impact although a lot of time and money were invested in trying to get teachers to change, very often with minimal results. It's clear today that one of the reasons for this is that those reforms were targeting behaviors without taking into consideration beliefs. So for all these reasons today we understand that, of course, what teachers do is important but if we want to understand what teachers do, if we want to promote change, we also need to look at beliefs. 
INTERVIEWER: In some of your studies (Borg, 2006; Phipps \& Borg 2009) you talked about teachers' beliefs and pointed out that they are understudied. Can you describe the situation?

SIMON BORG: If we compare our situation in language teacher education today with the situation in the mid-nineties, huge progress has been made. Even the quantity of research available today, compared to five years ago, I think there has been a huge increase in volume so I wouldn't say that there is little research on teachers' beliefs today. The progress in recent years has been encouraging and teachers' beliefs are being analyzed from a range of perspectives in language teaching in relation to many different aspects of teachers work.

INTERVIEWER: Do you think it is difficult to delve into teachers' beliefs?

SIMON BORG: The study of beliefs presents challenges mainly because beliefs are not directly observable. We can go into a classroom, we can observe behavior, we can see what the teachers do, we can describe that; but with beliefs we can't see them. We can't look at a teacher and know what they believe. Methodologically the challenges have been for us to find ways of eliciting beliefs and the only way we can do this is by getting teachers to tell us what their beliefs are, or to produce work in which their beliefs are implied. We can have direct strategies where we say to a teacher "what are your beliefs about communicative language or task based learning?', which present their own challenges because teachers may not very often be able to articulate their views in such a direct way. Many teachers have never been asked about their beliefs. Many teachers have never been given opportunities to articulate their beliefs and they may not be fully aware of them so when we as researchers turn up with a microphone and say (with a voice recorder) 'tell me what your beliefs about $\mathrm{x}$ are' it's not surprising that teachers struggle to put their thoughts into words. Direct strategies very often are not the most productive. We also have indirect strategies, I'm thinking of visual strategies for example - getting teachers to draw pictures, that is an indirect way of trying to access their beliefs. So if you say draw me a picture of an effective classroom or of a good teacher, then we can use that as the basis to explore teachers' beliefs. Given the choice between the two I have tended to find the indirect strategies more productive. In other words, rather than asking directly 'what are your beliefs', to use a stimulus of some kind, e.g. a piece of teaching material such as a lesson plan from the teacher's own work or an activity from a teacher's own class and then use that as the basis of exploring beliefs. Another challenge in studying beliefs is the difference between contextualized versus abstract concepts for talking about beliefs. If I ask a teacher what their beliefs about pair work are, the answer the teacher gives will most likely be an abstract, theoretical one. It is very common for them to say 'I believe that pair work is valuable I think it is something all teachers should do'. However if I visit that teacher's classroom, observe some of their teaching and ask them the same question in relation to their own 
practice, I may get a very different answer. The answer I may get would be, 'in my context, not feasible or for various reasons it is not something that I do'; and I do think it is an important methodological conceptual distinction for us to keep in mind.

INTERVIEWER: What do core beliefs and peripheral beliefs refer to? What are their main characteristics? What type of beliefs are they?

SIMON BORG: The basic distinction between core and peripheral is in simple terms one of strength. Our core beliefs are the ones that are more stable and powerful in what we do. Our peripheral beliefs are, in contrast, perhaps less stable, perhaps issues that we are less committed to and which we might compromise on when tensions arises between a peripheral belief and a core belief. So I think it is a matter of strength and it will vary enormously from individual to individual. In some cases the core beliefs may relate to educational issues more generally, whereas the beliefs we hold specifically about language learning may sometimes actually be peripheral.

INTERVIEWER: Do you think that core beliefs are not only more general, deeper and some other core or peripheral beliefs can depend on them?

SIMON BORG: The volume of research on the distinction between core and peripheral in language teaching context is very limited still. We have some insights from education or psychology but in terms of empirical evidence in our field this is really still quite a new issue. I did a paper on this theme with Simon Phipps in 2009. In that paper we had teachers saying 'I believe that the teacher should speak English most of the time' but then the teacher also believes that the student is perhaps more reassured when the teacher is able to explain grammar in the L1, where teachers and students share an L1. In that case we have a core belief about the importance of reassuring students, keeping them happy, versus a more peripheral belief about the importance of using the L1. When those two are put in tension it's the core belief that seems to be more powerful with the result that, in practice, the teacher doesn't try to minimize the use of L1, although theoretically she says she does. So that belief is not a very strong one. In another study I was working on with a colleague in Japan about grammar teaching, the teacher was saying that communicative activities are useful but in our context we need to cover material very quickly and in a way that students understand. So we don't do pair work, we explain grammar and we explain it in Japanese and we move along as quickly as possible; so again you've got these tensions.

INTERVIEWER: Tensions between beliefs and teachers' practice are a reflection of their subsystems of beliefs, in which way do the two subsystems - i.e., core and peripheral beliefs - start being in tension? And why do the two subsystems manifest themselves by creating this tension between beliefs and practice? 
SIMON BORG: We have got the idea of tensions between different subsets of beliefs and the idea that a belief system may be internally inconsistent so we have belief systems, but within those systems inconsistency is not unusual. We may believe one thing, but we may also believe something else that pulls in a different direction. There are teachers who say it is important to get learners to discover grammar for themselves but it is also important for me to cover the curriculum quickly so there is a tension there between a belief in the need for efficiency and another belief. So these tensions tend to arise simply because of the very nature of belief systems, they are almost naturally disposed to a certain amount of inconsistency that reflects the complexity of teacher cognition. The idea that teachers have a consistent set of beliefs, which regulate what they do in some consistent manner, is very simplistic. The situation is much more complex than that and so I have been keen to talk about tensions in a way that doesn't make them sound like they represent a defect in teachers' work or in teachers' thinking. We all have tensions in our beliefs, we all have tensions between our beliefs and our practices; so I think we need to accept that as something that it is just normal rather than making a big fuss because we find out that the teacher has inconsistent beliefs so they don't do what they say they believe. I think what we need to be doing, from a researcher's point of view, is research to understand how different subsets of beliefs work and coexist and part of our work in teacher education is helping teachers become aware of this. It is not simply a research exercise for me, there is a practical goal here in terms of how we improve the quality of the support we provide teachers and this is a good example of how research serves a very practical purpose.

INTERVIEWER: Do these tensions appear only in relation to the teaching of grammar? Why?

SIMON BORG: It is definitely not a concept that applies only to grammar teaching, it is a sort of universal concept. At the moment it just happens to be the case in grammar teaching because grammar teaching is one of those issues which has perhaps been the focus of most debate in our field and therefore that is why perhaps it has been a popular candidate for studies of teachers' beliefs. If we look at a lot of educational reform in language teaching, very often at the core of the reform is some desire to change the way grammar is conceptualized, to change the way grammar is handled by teachers. If we are talking about introducing communicative practices or task based practices centrally implied in all of those reforms is a change in the way grammar is viewed. That is perhaps why grammar is a good candidate for studying teachers' beliefs because teachers will always have views about grammar; it is a topic which has been central in the field for a very long time and which will continue to be. Having said that, there is no reason why tensions cannot be studied in other aspects of language teaching, for example the teaching of speaking.

INTERVIEWER: What impact do contextual factors have on teachers' practice? 
SIMON BORG: It is very well established from the research available that there is not much point in studying the relationship between beliefs and practices if we omit context from that equation. We will end up with a partial understanding of what is going on because the relationship between beliefs and practices is not a direct and linear one so we know that context mediates that relationship and so whenever we are setting up studies of beliefs and practices we must build attention to context into that equation. If we look at the research that is available we can compile a long list of different types of contextual factors which may mediate teachers' beliefs and they can go from the quite broad down to a very specific classroom level. There is a whole range of contextual factors at different levels which may come into play.

INTERVIEWER: What other beliefs are related to grammar beliefs?

SIMON BORG: We can never explain what teachers do in relation to one single belief. There are sets of beliefs interacting: beliefs about learners and learning, beliefs about materials, beliefs about assessment, beliefs about different aspects of language learning, speaking, reading, writing, vocabulary, beliefs about all kinds of things. The challenge for us as a researchers is try to understand that complex puzzle, which is different for every teacher and that is what makes this kind of work interesting because you can talk to ten teachers even if they are working in the same school and you are going to get ten different puzzles.

INTERVIEWER: Many of the studies cited in your book of 2006 agree with the fact that teachers have an inadequate level of grammatical knowledge and that sometimes they are not even aware of it. How do these aspects influence teachers' practice?

SIMON BORG: Knowledge is a sensitive issue in research terms. If I approach teachers in a school and I say I would like to do some research on your knowledge of grammar I am very unlikely to find any volunteers. A way of doing it indirectly is by observing teachers. We go into the classroom, we observe what they do when they are teaching grammar and we analyze the quality of the explanations, the quality of the examples, the accuracy of the information they provide. It can give us a measure of knowledge in practice that teachers have with grammar and that is a more feasible way of doing it. Having said all of this, there is no doubt that the knowledge we have of a subject must influence how we teach. I think research in education generally does provide evidence that subject matter knowledge is a powerful determinant of teaching quality. We can't really teach something we don't know about and it is a very important issue for us in the field to make sure that teachers at pre-service level are given the opportunities to develop their knowledge of and about language and that in-service level they are given regular opportunities to continue thinking about language. I am not sure that particularly in in-service level knowledge about languages is given the importance it deserves. The focus very often is on methodology on how to teach and we could benefit by having more opportunities for teachers in a constructive way to focus on developing their own 
understandings of grammar. There is no doubt that knowledge about language does influence how we teach it. The other issue is not just about what teachers know; it is how much they believe they know. There is the issue of self-efficacy and confidence which means that I have seen teachers whose knowledge of grammar is shaky but they don't seem to be aware of it, therefore they teach inaccurately but very comfortably.

INTERVIEWER: In some of your papers (Borg, 2003, 2006, 2011), you commented on the importance of conducting longitudinal studies. Why do you think longitudinal studies are important? What relevant findings might this type of studies yield? How should longitudinal studies be conducted?

SIMON BORG: There are certain processes in education, which by definition unfold overtime -learning is an obvious one. In order to understand such processes a longitudinal approach is the only feasible option. If you are working with a group of teachers in a teacher education context and you want to see development or change in learning in some aspect of their work or their practices, their beliefs, their knowledge, it is unrealistic to expect to see that in the short term. Very often pre-service teachers are sent out on a teaching practice which lasts perhaps two, three or four weeks. My view is that may not be long enough to for evidence of learning to emerge. However, I am not saying that we shouldn't use that because it is the time available. Learning happens in an irregular manner, in a zigzag pattern or a u-shaped curve or going backwards and forwards. It is not linear over time; to get a sense of development we have no option but to look at things longitudinally. Longitudinal studies are valuable because they provide insights into teacher learning over time and this is a central concern to us. Some of the few studies which have a longitudinal dimension are very often questionnaire based. I will give my student teachers a questionnaire once a year for four years and that is interesting but I don't think it provides the qualitative insight which we really need. It doesn't really give me insights into what kinds of learning opportunities or experience the teachers had that influenced those changes and the answers are going to be complicated because I don't think that one learning experience in itself triggers an immediate strong and lasting change in belief. It is likely to be accumulative and I do think there is the space for us to be doing more work of this kind.

INTERVIEWER: Thank you very much for your time and your availability.

SIMON BORG: You're welcome.

\section{References:}

Borg, S. (2003). Teacher cognition in language teaching: A review of research on what language teachers think, know, believe and do. In Language Teaching, 36 (2), 81 $-109$.

Borg, S. (2006). Teacher cognition and teacher education: research and practice. London: Continuum. 
Borg, S. (2011). The impact of in-service education on language teachers' beliefs. In System, 39 (3), 370-380.

Phipps \& Borg, S. (2009). Exploring tensions between teachers' grammar beliefs and practice. In System, 37 (3), 380-390.

\section{Author References:}

Marilisa Birello is a postdoctoral assistant professor in the Departament de Didàctica de la Llengua i la Literatura i les Ciències Socials at the Universitat Autònoma of Barcelona. She teaches courses in language teaching methodology. She has participated in various research projects focused on reflective practices in language learning and language teaching conducted in several Catalan and overseas universities. Her research interests include language teacher training, languages in contact and conversational analyses in multicultural and multilingual contexts. She has published articles in scholarly journals and books edited by Routledge and Peter Lang.

\section{Email: marilisa.birello@uab.cat}

To cite this article:

Birello, M. (2012). Teacher Cognition and Language Teacher Education: beliefs and practice. A conversation with Simon Borg. Bellaterra Journal of Teaching \& Learning Language \& Literature, 5(2), $88-94$. 